\title{
MÉTODO PARA DETERMINAÇÃO DE CARBOIDRATOS EMPREGADO NA TRIAGEM DE
} ADULTERAÇÕES EM CAFÉ

\author{
Elis Daiane Pauli, Valderi Cristiano e Suzana Lucy Nixdorf*
}

Departamento de Química, Centro de Ciências Exatas, Universidade Estadual de Londrina, CP 6001, 86051-970 Londrina - PR, Brasil

Recebido em 7/5/10; aceito em 22/9/10; publicado na web em 7/1/11

\begin{abstract}
METHOD FOR DETERMINATION OF CARBOHYDRATES EMPLOYED IN THE SELECTION OF ADULTERATIONS IN COFFEE. The objective in this work was to validate a chromatography method for the determination of total carbohydrates in soluble coffee, using a HPLC-UV-VIS with postcolumn derivatization system, in order to verify adulterant additions. The validated method was accurate and robust. Adulteration could be observed by increasing xylose and glucose levels in samples with addition of coffee husks and starchy products while decreasing of galactose and mannose characteristic carbohydrates presenting in high concentration in soluble coffees produced by arabica and robusta coffee beans.
\end{abstract}

Keywords: adulterants; carbohydrates; HPLC-UV-VIS.

\section{INTRODUÇÃO}

O café é uma das bebidas mais populares consumidas no mundo ${ }^{1}$ conhecida por ser símbolo de hospitalidade, estimulante e, mais recentemente, pelos efeitos benéficos à saúde atribuídos a componentes bioativos. ${ }^{2}$ No comércio internacional, é um dos produtos básicos mais valiosos, ou seja, é a segunda maior commodity no mundo, permanecendo atrás somente do petróleo. ${ }^{3,4} \mathrm{O}$ Brasil por sua vez, é o maior produtor mundial de café, sendo responsável por aproximadamente $30 \%$ do mercado internacional. ${ }^{5}$

O elevado valor comercial do café o torna atrativo para ações fraudulentas. Por fraude, considera-se a mistura, intencional ou não, de materiais estranhos ao produto, normalmente de baixo custo, que alteram a sua qualidade e causam danos ao consumidor, especialmente, os de ordem econômica. ${ }^{6}$ As misturas são os produtos adicionados ao café para fraudá-lo, enquanto impurezas são substâncias resultantes do mau beneficiamento do produto, como cascas, paus, torrões, que em grandes quantidades pressupõem fraude intencional. ${ }^{7}$ No caso do Brasil os produtos mais acrescentados ao café torrado e moído são cascas, paus, milho, cevada, triguilho, açúcar mascavo e soja. ${ }^{6,7}$

De acordo com Bernal et al. ${ }^{8}$ e Garcia et al., ${ }^{9}$ a determinação individual de carboidratos tem importância significativa não somente por prover informação composicional das amostras, mas também, por auxiliar na identificação de adulterantes. Nos últimos anos têm sido feitas diversas pesquisas relacionadas ao perfil dos carboidratos especialmente de cafés solúveis, devido à enorme gama destes tipos de produtos comercialmente disponíveis, necessitando de métodos analíticos para classificá-los, monitorar a presença de componentes diferentes do café e definir os limites de um produto não adulterado. ${ }^{10}$

Os carboidratos podem, segundo Bernal et al., ${ }^{8}$ ser determinados utilizando-se cromatografia líquida de alta eficiência (HPLC - High Performance Liquid Chromatography) com combinações apropriadas da fase estacionária e do sistema da detecção. Pelo fato dos carboidratos não apresentarem ligações $\pi$ conjugadas, não podem ser diretamente detectados por espectroscopia no ultravioleta visível (UV-

*e-mail: snixdorf@uel.br
VIS) requerendo, assim, derivatizações capazes de gerar subprodutos fotometricamente ativos. A aplicação do reagente (4-Aminobenzoil) hidrazida na derivatização pós-coluna em matrizes complexas tem como objetivos: a simplificação no preparo das amostras, não requerendo desproteinização; o aumento da especificidade, com redução de interferentes; e o aumento na sensibilidade, elevando em 10 vezes os níveis de detecção comparativamente ao índice de refração, ${ }^{11}$ por produzir ânions cromóforos amarelos, ${ }^{12}$ detectados após separação em coluna catiônica.

Já a cromatografia de troca aniônica acoplada com detecção eletroquímica por amperometria pulsada (HPAE-PAD - High Performance Anion-Exchange Chromatography with Pulsed Amperometric Detection) tem sido a técnica adotada internacionalmente para análise de carboidratos em café solúvel, cujo método normalizado é o ISO $11292,{ }^{13}$ por exigir pouco preparo da amostra, apresentar resolução e sensibilidade sem necessitar de derivatizações. ${ }^{14}$

Contudo, grandes variações nos teores dos carboidratos são observadas de acordo com a utilização dos diferentes sistemas instrumentais, condições de processo e analíticas, a exemplo do estudo realizado por Blanc et al ${ }^{15}$ com café arábica torrado empregado na produção de café solúvel utilizando HPLC-UV-VIS pós-coluna, que mostra teores que variam em $\%(\mathrm{~m} / \mathrm{m})$ de: $1,29-2,00$ para glicose; 0,08-0,14 para xilose; 3,19-20,93 para galactose; 1,03-6,29 para arabinose; 5,91-19,50 para manose, dependendo das condições de tempo de extração - 30 a 240 min e temperatura - 150 a $190{ }^{\circ} \mathrm{C}$. Redgwell et $a l .{ }^{16}$ encontraram a composição de monossacarídeos por HPAE-PAD, após hidrólise com $72 \% \mathrm{H}_{2} \mathrm{SO}_{4}$ por $3 \mathrm{~h}$ à temperatura ambiente e 2

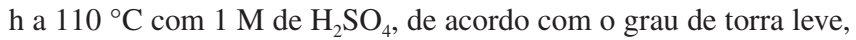
média e escura, e o tipo de café utilizado em $\%(\mathrm{~m} / \mathrm{m})$ de: glicose de 6,10-8,01; xilose de 1,10-3,65; galactose de 5,50-12,10; arabinose de 0,74-4,29 e manose de 15,97-24,89.

Segundo descrito por Arya e Rao, ${ }^{10}$ as elevadas temperaturas no processo de café solúvel levam à hidrólise das frações de polissacarídeos, gerando elevados teores dos monossacarídeos arabinose, galactose e manose. O café solúvel puro é caracterizado pelos altos valores de galactose e manose total. ${ }^{17}$ Assim, dependendo do perfil dos carboidratos estes podem ser separados em 2 grupos: os com 
altos teores de xilose e glicose adulterados com cascas e, os com altas concentrações de glicose total e baixos de xilose, adulterados com materiais constituídos de amido, carboidrato de alto peso molecular. ${ }^{10}$ Segundo Prodolliet e Hischenhuber, ${ }^{17}$ a autenticidade do café solúvel pode ser comprovada pelos limites máximos aceitáveis de xilose, manitol e glicose total nas concentrações de 0,$40 ; 0,30$ e 2,10\%, respectivamente. Estes limites foram considerados para o estabelecimento do Código de Práticas para a Indústria de Café Solúvel no Reino Unido, que considera além destes um teor máximo aceitável para a frutose livre de $0,60 \%$. Para a Associação dos Países Fabricantes de Café Solúvel da Comunidade Europeia (AFCASOLE), ${ }^{18}$ a autenticidade do café solúvel pode ser comprovada pelos limites máximos aceitáveis de frutose livre, xilose total e glicose total nas concentrações de 0,$60 ; 0,40$ e $2,10 \%$, respectivamente.

O objetivo do presente trabalho foi validar uma metodologia não normalizada, para ser aplicada com credibilidade e de forma adequada em rotina, ${ }^{19,20}$ seguindo parâmetros do INMETRO, ${ }^{21}$ empregada para a determinação de carboidratos por HPLC-UV-VIS com reação pós-coluna, para fins de triagem de autenticidade da qualidade de cafés solúveis, baseada no perfil e teores limites estabelecidos pela AFCASOLE. ${ }^{18}$

\section{PARTE EXPERIMENTAL}

\section{Preparo das amostras}

A validação do método foi feita utilizando uma amostra de café solúvel comercial $100 \%$ arábica preparada seguindo os parâmetros descritos na norma ISO 11292, ${ }^{13}$ adaptada para a etapa de extração e hidrólise. A determinação do teor de umidade foi feita empregando Karl Fisher. ${ }^{22}$ Para a extração pesou-se 0,2000 $\pm 0,001 \mathrm{~g}$ de amostra em base seca e transferiu-se para um erlenmeyer de $250 \mathrm{~mL}$, adicionou-se à amostra 10,0 mL de solução de ácido clorídrico 0,6 $\mathrm{mol} \mathrm{L}{ }^{-1}$. A amostra foi hidrolisada em autoclave por 120 min à pressão $\mathrm{de} \cong 1 \mathrm{Kgf} \mathrm{a} 121^{\circ} \mathrm{C}$. A amostra resfriada à temperatura ambiente foi transferida para um balão volumétrico de 100,00 mL e completou-se o volume com água ultrapura Milli-Q (Millipore, MA, EUA). Pipetouse $10,00 \mathrm{~mL}$ de amostra, que foi neutralizada com o uso de 1,00 \pm $0,01 \mathrm{~g}$ de resina aniônica regenerada com $\mathrm{NaOH}$, filtrada em papel faixa branca, passada em cartucho Sep-Pak C18 (Waters, Milford, EUA) pré-condicionado com metanol e água, e em membrana 0,22 $\mu \mathrm{m}$ (GVWP 02500 - Millipore, MA, EUA), descartando-se as primeiras gotas e levando ao sistema cromatográfico para análise. Este foi o procedimento considerado padrão utilizado para a análise das amostras de cafés solúveis, puros e adulterados, todas de procedência comercial adquiridas de diferentes países.

\section{Padrões}

Os padrões empregados foram procedentes da Merck (Darmstadt, Alemanha): D(-) - Manitol, D(-) - Arabinose, D(+) - Galactose, $\mathrm{D}(+)$ - Glicose, $\mathrm{D}(+)$ - Xilose, $\mathrm{D}(+)$ - Manose, D(-) - Frutose, com 99,90; 99,90; 98,00; 99,50; 99,00; 99,50; 99,45 e 99,90\% de pureza, respectivamente. Para a quantificação dos carboidratos nas amostras, preparou-se uma solução padrão com concentrações similares às encontradas nas amostras de café solúvel. Os padrões de carboidratos foram pesados: $0,030 \pm 0,001 \mathrm{~g}$ de glicose, $0,020 \pm 0,001 \mathrm{~g}$ de xilose, $0,110 \pm 0,001 \mathrm{~g}$ de galactose, $0,040 \pm 0,001 \mathrm{~g}$ de arabinose $\mathrm{e}$ $0,060 \pm 0,001 \mathrm{~g}$ de manose, transferidos para um balão volumétrico de $100,00 \mathrm{~mL} \pm 0,50 \mathrm{~mL}$ e o volume foi completado com água ultrapura. Sonicou-se a solução por $5 \mathrm{~min}$ em banho ultrassônico. $\mathrm{O}$ padrão foi armazenado em geladeira a $\sim 4{ }^{\circ} \mathrm{C}$. Esta solução estoque foi diluída para a obtenção do padrão analítico de $25 \%(\mathrm{v} / \mathrm{v})$ o qual foi injetado a cada dia utilizado para a quantificação. A partir dessa solução padrão estoque foram feitas diluições para o levantamento das curvas analíticas, que possibilitaram a determinação da linearidade na faixa dinâmica de trabalho e do limite de quantificação empregados nas análises cromatográficas.

\section{Fases móveis}

Adotou-se a água ultrapura (Milli-Q ${ }^{\circledR}$ ) como fase móvel eluente por apresentar a melhor resolução cromatográfica, filtrada em membrana 0,45 $\mu \mathrm{m}$ de éster de celulose (Millipore, Billerica, MA), submetida a vácuo e sonicação em banho ultrassônico simultaneamente para desgaseificação por 5 min. Para o sistema pós-coluna a derivatização empregou como fase móvel uma mistura de duas soluções, a primeira contendo 1,250 g de (4-Aminobenzoil)-hidrazida ( $\mathrm{ABH}$ ) (4-aminobenzoyl)hydrazide, $\mathrm{C}_{7} \mathrm{H}_{9} \mathrm{~N}_{3} \mathrm{O}, 95 \%$, Acrós Organics), em 50,0 mL, adicionando-se 1,00 mL de ácido clorídrico 37\% (Merck, Alemanha, Darmstadt), dissolvendo-se em banho ultrassônico e completando-se o volume com água ultrapura; e a segunda com 4,80 g de hidróxido de sódio (Merck, Alemanha, Darmstadt), em escamas, e 0,730 g de cloreto de sódio (Merck, Alemanha, Darmstadt) em 100,0 mL de água ultrapura. A solução foi dissolvida em banho ultrassônico, filtrada em membrana 0,45 $\mu \mathrm{m}$ de éster de celulose (Millipore, Billerica, MA) e mantida resfriada até o momento de uso. Apesar do exato mecanismo de reação baseado na elucidação da estrutura dos produtos derivados não ter sido reportada por Lever, ${ }^{23}$ o qual propôs que a reação dos carboidratos redutores com certos tipos de hidrazidas de ácidos aromáticos, em meio fortemente básico, produzia a coloração amarela; nem por Vrátný et al., ${ }^{12}$ que otimizou sua aplicação como reagente de detecção sem, contudo, estudar suas características espectrais e cinéticas; segundo Honda, ${ }^{24}$ esta coloração é atribuída devido à formação com carboidratos de espécies aniônicas cromóforas de hidrazonas. Lever $^{23}$ mostrou que o ABH apresentou a melhor combinação entre a fase estacionária/fase móvel eluente água versus reagente pós-coluna, apresentando maior especificidade e relação sinal-ruído em $410 \mathrm{~nm}$. A utilização do agente cromogênico $\mathrm{ABH}$ na derivatização pós-coluna demonstrou ser aplicável a todos os carboidratos redutores, de forma mais rápida (3 min), apresentado maior sensibilidade (4,3x 10 ${ }^{-11} \mathrm{mols}$ de sacarose), comparado a outros derivatizantes utilizados, como o BCA (bicinconinato dissódico) que provoca distorção de picos e entupimento; o HCF (hexaferrocianato de potássio) que apresenta alto nível de ruído e interferentes, o TTB (azul de tetrazólio) solúvel somente em $\mathrm{NaOH}$ etanólico, o que causa alteração gradual da cor, provocando aumento de linha de base, e exige altas vazões de eluente; e o CAA (2-cianoacetamida) limitado a amostras que contenham cetoses, ${ }^{12}$ além de outras desvantagens, como a corrosão de equipamentos utilizando meio de ácido forte para conversão a furfural, seguida da condensação com reagentes cromóforos descrita por Honda. ${ }^{24}$

\section{Sistema instrumental}

O sistema instrumental utilizado consistiu em um cromatógrafo líquido de alta eficiência composto de dois frascos âmbar para armazenagem da fase móvel eluente e pós-coluna; duas bombas de alta pressão Waters 515 (Milford, MA, EUA); um injetor automático Waters 717 Plus; uma pré-coluna SP 1010 P (6 x 50 mm; Shodex; NY, EUA); uma coluna de troca iônica Aminex $\operatorname{HPX-87P(7,8~x~} 300$ $\mathrm{mm}$ na forma iônica $\mathrm{Pb}^{2+}$, Biorad, CA, EUA); um tee misturador; um forno termostatizado para coluna, acoplado com um controlador de temperatura módulo II Waters; um reator pós-coluna CRX 390 (Pickering Laboratories, Mountain View, CA, EUA) contendo uma bobina de reação de PTFE no interior do reator de temperatura controlada; regulador de pulso (pulse dampener) e restritor de pressão de 100 psi 
(back pressure) conectado na saída do detector; um detector UV-VIS Waters 2487; e o software Empower Build 1154, para aquisição e tratamento de dados por um microcomputador.

\section{Parâmetros analíticos empregados para as análises cromatográficas}

A validação da metodologia não normalizada, para a análise de carboidratos em café solúvel utilizando a técnica HPLC-UV-VIS pós-coluna, empregou os parâmetros de extração e análise apresentados nas Tabelas 1 e 2 denominado de procedimento padrão, pela adoção e adaptação das condições de reação pós-coluna, descritas por Femia e Weinberger. ${ }^{11} \mathrm{e}$ estudos de desempenho dependentes do instrumental feitos para otimização do ABH por Vrátný et al., ${ }^{12}$ aplicando os princípios de Lever. ${ }^{23}$ As variações apresentadas foram efetuadas para avaliação da robustez, considerando os testes de aplicabilidade prática ${ }^{12}$ e os fatores críticos de análise e suas potencialidades descritos na revisão de Honda,${ }^{24}$ como controle da vazão e da temperatura do reator pós-coluna.

\section{RESULTADOS E DISCUSSÃO}

\section{Validação}

A validação do método foi feita considerando os parâmetros de linearidade na faixa de trabalho, seletividade, especificidade, sensibilidade, exatidão, precisão e precisão intermediária, limite de detecção, limite de quantificação e robustez para as condições padrão.

A Tabela 3 apresenta as Equações das regressões lineares utilizadas na faixa dinâmica de trabalho para a glicose, xilose, galactose, arabinose e manose, demonstrando sua linearidade, com coeficientes de correlação superiores a 0,99 . Pela inclinação das retas observa-se que o carboidrato mais sensível entre os cinco analisados foi a glicose.

O limite de detecção calculado para a galactose foi de $0,07 \%$ $(\mathrm{m} / \mathrm{m})$, considerando-se três vezes a relação sinal/ruído ${ }^{20} \mathrm{O}$ limite de quantificação considerando-se o ponto de concentração mais baixo da curva de calibração foi de $0,13 \%(\mathrm{~m} / \mathrm{m})$ para xilose. ${ }^{21}$

A faixa linear de trabalho do método analítico, calculada de acordo com o INMETRO ${ }^{21}$ no intervalo entre os níveis inferior e superior da curva de calibração, foi dada pelos valores apresentados na Tabela 3 , com o menor de $2,6 \mu \mathrm{g} \mathrm{mL} \mathrm{mL}^{-1}$ ou $0,13 \%(\mathrm{~m} / \mathrm{m})$ para xilose e maior de $481,2 \mu \mathrm{g} \mathrm{mL}^{-1}$ ou $24,06 \%(\mathrm{~m} / \mathrm{m})$ para galactose.

A precisão foi determinada pela repetitividade de 7 injeções sucessivas de amostras de café solúvel comercial $100 \%$ arábica extraídas pelo procedimento padrão, obtendo-se os coeficientes de variação de 4,$95 ; 9,10 ; 1,94 ; 2,87$ e $1,22 \%(\mathrm{~m} / \mathrm{m})$ para glicose, xilose, galactose, arabinose e manose, respectivamente. A precisão intermediária, calculada a partir da injeção em 9 dias diferentes de uma amostra de café solúvel comercial $100 \%$ arábica, apresentou coeficientes de variação de 6,$43 ; 10,06 ; 4,07 ; 6,90$ e $5,83 \%(\mathrm{~m} / \mathrm{m})$ para glicose, xilose, galactose, arabinose e manose, respectivamente, inferiores a $15 \%$, valor adotado como referência de acordo com a Resolução $n^{\circ}$ 899 , de 29/5/2003, da Anvisa. ${ }^{25}$

Tabela 1. Condições e parâmetros analíticos empregados na extração dos carboidratos em amostra de café solúvel comercial 100\% arábica e suas respectivas variações

\begin{tabular}{ccc}
\hline Condições de extração & $\begin{array}{c}\text { Parâmetros adotados } \\
\text { (procedimento padrão) }\end{array}$ & Variações \\
\hline Concentração de ácido clorídrico de hidrólise $\left(\mathrm{mol} \mathrm{L}^{-1}\right)$ & 0,6 & $0,4-0,8$ \\
Equipamento de hidrólise & autoclave vertical & Banho-maria termostático \\
Temperatura de hidrólise $\left({ }^{\circ} \mathrm{C}\right)$ & 121 & 100 \\
Tempo de hidrólise (h) & 2 & $\pm 20 \%$ e não considerando umidade \\
Massa da amostra em base seca & $0,200 \mathrm{~g} H=1,5$ e pH $=3,5$ \\
pH final da amostra & neutralizada (pH $=7,0)$ & não empregando \\
Cartucho Sep Pak C-18(Waters) & empregado &
\end{tabular}

Tabela 2. Condições cromatográficas adotadas para a análise dos carboidratos em amostra de café solúvel comercial 100\% arábica e suas respectivas variações

\begin{tabular}{ccc} 
Condições de análise & $\begin{array}{c}\text { Parâmetros de análise } \\
\text { (procedimento padrão) }\end{array}$ & Variações \\
\hline Volume de injeção $(\mu \mathrm{L})$ & 20,0 & $15,0-25,0$ \\
Vazão da fase móvel eluente da coluna - água ultrapura $\left(\right.$ Milli-Q) - Bomba 1 $\left(\mathrm{mL} \mathrm{min}{ }^{-1}\right)$ & 0,5 & $0,4-0,6$ \\
Vazão da fase móvel pós-coluna $-\mathrm{NaOH}+\mathrm{ABH}-\mathrm{Bomba} 2\left(\mathrm{~mL} \mathrm{~min}{ }^{-1}\right)$ & 0,6 & $0,5-0,7$ \\
Temperatura da coluna (forno) $\left({ }^{\circ} \mathrm{C}\right)$ & 85 & $83-87$ \\
Temperatura do reator pós-coluna $\left({ }^{\circ} \mathrm{C}\right)$ & 100 & $95-105$ \\
\hline
\end{tabular}

Tabela 3. Parâmetros utilizados para a verificação da linearidade na faixa dinâmica de trabalho, utilizados para o levantamento das curvas de calibração feitas a partir da mistura de padrões dos cinco carboidratos injetados em triplicata

\begin{tabular}{|c|c|c|c|c|c|c|c|c|c|c|}
\hline \multirow{2}{*}{$\begin{array}{c}\text { Carboidratos } \\
\text { Glicose }\end{array}$} & \multicolumn{7}{|c|}{ Concentração de carboidratos em \% (m/m) } & \multirow{2}{*}{$\begin{array}{l}\text { Regressão } \\
485,67 x-8391,58\end{array}$} & \multirow{2}{*}{$\begin{array}{c}\mathrm{r} \\
0,9996\end{array}$} & \multirow{2}{*}{$\begin{array}{c}\begin{array}{c}\text { Faixa dinâmica } \\
\left(\mu \mathrm{g} \mathrm{m} \mathrm{m}^{-1}\right)\end{array} \\
3,8-131,2\end{array}$} \\
\hline & 0,19 & 0,75 & 0,94 & 1,88 & 3,75 & 5,63 & 6,56 & & & \\
\hline Xilose & 0,13 & 0,50 & 0,63 & 1,25 & 2,50 & 3,75 & 4,38 & $y=33124,06 x-8356,88$ & 0,9999 & $2,6-87,6$ \\
\hline Galactose & 0,69 & 2,75 & 3,44 & 6,88 & 13,75 & 20,63 & 24,06 & $y=190629,97 x-6309,10$ & 0,9993 & $13,8-481,2$ \\
\hline Arabinose & 0,25 & 1,00 & 1,25 & 2,50 & 5,00 & 7,50 & 8,75 & $y=246050,89 x+4451,33$ & 0,9993 & $5,0-175,0$ \\
\hline Manose & 0,38 & 1,50 & 1,88 & 3,75 & 7,50 & 11,25 & 13,13 & $y=233222,94 x-3525,05$ & 0,9996 & $7,6-262,6$ \\
\hline
\end{tabular}


Tabela 4. Exatidão pelo procedimento de recuperação, calculada a partir das concentrações realizadas em triplicata

\begin{tabular}{cccccc}
\hline Carboidratos & $\begin{array}{c}\text { Média não fortificada } \\
(\%)(\mathrm{m} / \mathrm{m})\end{array}$ & $\begin{array}{c}\text { Concentração } \\
\text { adicionada } \\
(\%)(\mathrm{m} / \mathrm{m})\end{array}$ & $\begin{array}{c}\text { Concentração } \\
\text { esperada } \\
(\%)(\mathrm{m} / \mathrm{m})\end{array}$ & $\begin{array}{c}\text { Média fortificada } \\
(\%)(\mathrm{m} / \mathrm{m})\end{array}$ & $\begin{array}{c}\text { Taxa de recuperação } \\
(\%)\end{array}$ \\
\hline Glicose & 1,29 & 1,50 & 2,85 & 2,70 & 96,71 \\
Xilose & 0,29 & 1,00 & 1,33 & 1,30 & 21,87 \\
Galactose & 17,13 & 5,50 & 21,29 & 4,95 & 100,71 \\
Arabinose & 2,78 & 2,00 & 4,74 & 16,53 & 103,49 \\
Manose & 13,75 & 3,00 & 15,57 & 98,73 \\
\hline
\end{tabular}

Tabela 5. Teores médios de carboidratos encontrados pela determinação empregando HPLC-UV-VIS pós-coluna, feitas em duplicata em café solúvel comercial puro e adulterado com misturas de derivado de amido e cascas de café

\begin{tabular}{cccccc}
\hline $\begin{array}{c}\text { Carboidrato } \\
\%(\mathrm{~m} / \mathrm{m})\end{array}$ & $\begin{array}{c}\text { Padrão de } \\
\text { carboidratos }\end{array}$ & $\begin{array}{c}\text { Café solúvel } \\
100 \% \text { arábica }\end{array}$ & $\begin{array}{c}\text { Café solúvel } \\
100 \% \text { robusta }\end{array}$ & $\begin{array}{c}\text { Café solúvel adulterado } \\
\text { com amiláceos }\end{array}$ & $\begin{array}{c}\text { Café solúvel adulterado } \\
\text { com casca de café }\end{array}$ \\
\hline Glicose & 3,75 & 1,46 & 1,78 & 18,90 & 2,82 \\
Xilose & 2,50 & n.d. & n.d. & 0,63 & 6,08 \\
Galactose & 13,75 & 19,59 & 17,99 & 10,18 & 10,13 \\
Arabinose & 5,00 & 3,87 & 3,53 & 1,70 & 4,47 \\
Manose & 7,50 & 17,99 & 12,83 & 5,19 & 3,44 \\
\hline
\end{tabular}

n.d. = não detectado

A especificidade foi avaliada pela análise individual de cada carboidrato verificando seu tempo de retenção, os quais não apresentaram nenhum outro pico além do carboidrato injetado.

A exatidão foi calculada pela recuperação, feita a partir da adição dos padrões à amostra analisada, calculada pela Equação e apresentada na Tabela 4, permanecendo entre os limites de 70,00 a 120,00\% previstos para que um método seja considerado exato. ${ }^{21}$

$$
\operatorname{rec}(\%)=\frac{\left(\mathrm{C}_{1}-\mathrm{C}_{2}\right) \times 100}{\mathrm{C}_{3}}
$$

onde: $r e c=$ recuperação; $C_{1}=$ concentração determinada na amostra com adição de padrão; $C_{2}=$ concentração determinada na amostra original sem adição de padrão; $C_{3}=$ concentração adicionada.

A seletividade foi verificada pela ausência de resposta no tempo de retenção de cada um dos carboidratos comparando-se com o padrão analítico de $25 \%$ (v/v), permanecendo em linha de base para a análise da água ultrapura e do ácido clorídrico $0,6 \mathrm{~mol} \mathrm{~L}^{-1}$ quando submetidos ao procedimento padrão de extração, concluindo-se que os reagentes utilizados para a hidrólise não interferiram na amostra.

O método foi considerado robusto considerando os resultados das variações descritas nas Tabelas 1 e 2 para os valores de $F_{\text {calculado }}<F_{\text {tabelado }}$ para o Teste $\mathrm{F}$, num intervalo de confiança de $95 \%$, das variâncias entre as matrizes de dados, seguido do Teste $t$ presumindo variâncias equivalentes para as variações de concentração de ácido clorídrico da hidrólise $\left( \pm 0,2 \mathrm{~mol} \mathrm{~L}^{-1}\right)$; massa em peso seco $( \pm 20 \%(\mathrm{~m} / \mathrm{m}))$; $\mathrm{pH}$ final da amostra $(1,5$ e 3,5); limpeza empregando cartuchos de extração em fase sólida; vazões das bombas das fases móveis da coluna cromatográfica $( \pm 0,1$ $\left.\mathrm{mL} \mathrm{min}^{-1}\right)$ e do sistema pós-coluna $\left( \pm 0,1 \mathrm{~mL} \mathrm{~min}^{-1}\right)$; e temperatura do forno da coluna $\left( \pm 2{ }^{\circ} \mathrm{C}\right)$. Estes resultados concordam com os de Vrátný et al., ${ }^{12}$ que verificaram que as curvas para os sacarídeos se mostraram insensíveis a pequenas variações de vazão.

Houve diferença nos valores empregando equipamentos distintos, autoclave vertical (Phoenix - modelo AV18) e banho termostático (Fanaem - modelo 146) e tempo de hidrólise (1 e 2 h). Portanto, os teores dependem das condições de hidrólise que afetam os resultados, o que concordou com a literatura, ${ }^{15,16}$ ressaltando a importância de se manter os parâmetros previamete padronizados.
A temperatura de $95{ }^{\circ} \mathrm{C}$ para o reator pós-coluna foi adotada nas condições padrão, baseando-se na instabilidade da linha de base à $100^{\circ} \mathrm{C}$, atribuída à formação de bolhas, descrita nos estudos de otimização feitos por Vrátný et al.. ${ }^{12}$ Contudo, como o estudo avaliando a dependência da temperatura da reação com o cromóforo revelou que o ponto ótimo não foi alcançado sob a faixa testada de 80 a $100{ }^{\circ} \mathrm{C}$, uma vez que, o tempo de reação ( $40 \mathrm{~s}$ ) foi significativamente menor que o platô determinado pelo procedimento manual, a sugestão foi que novos testes fossem realizados em sistema automatizado. Considerando que a reação de derivatização pós-coluna deve ocorrer após a separação e antes da detecção, ${ }^{24}$ por ser automatizado, o sistema de HPLC utilizado no trabalho atende a este requisito, permitindo que a reação se dê de forma apropriada, através da mistura contínua na bobina de reação em temperatura e velocidade controladas, reduzindo assim a dispersão. ${ }^{12}$ Conhecendo-se que a reação é dependente da temperatura, com teoricamente seu ponto ótimo próximo ao ponto de ebulição da solução reativa, ${ }^{24}$ a instabilidade da linha de base devido a bolhas e turbulência foi minimizada pela utilização de dispositivo restritor na saída do detector, produzindo aumento de pressão que, associado à adição do sal $(\mathrm{NaCl})$, geraram elevação da temperatura de ebulição da solução reativa, permitindo a realização de testes mantendo o reator a 100 e $105^{\circ} \mathrm{C}$.

Os cromatogramas da Figura 1 mostram que não houve flutuações de linha de base com a elevação da temperatura, porém a variação interferiu significativamente, gerando um ganho de sinal analítico, mostrando ser uma alternativa viável, caso o aumento de sensibilidade seja requerido. No entanto, em termos de robustez, exige a fixação em determinado patamar de temperatura, com rigoroso controle.

\section{Perfil qualitativo e análise quantitativa de carboidratos}

A Figura 2 apresenta os cromatogramas com os perfis dos monossacarídeos presentes nas amostras de café solúvel comerciais: $100 \%$ arábica; $100 \%$ robusta; adulterados com produtos à base de amido e com casca de café, quantificados pela mistura de padrões externos a $25 \%$ (v/v) (Tabela 5).

Observando o perfil dos 2 cafés comerciais puros (Figura $2 \mathrm{~b}$ e 2c), percebe-se que praticamente não há diferença entre eles, exceto pela manose que apresentou um teor ligeiramente maior. É possível 


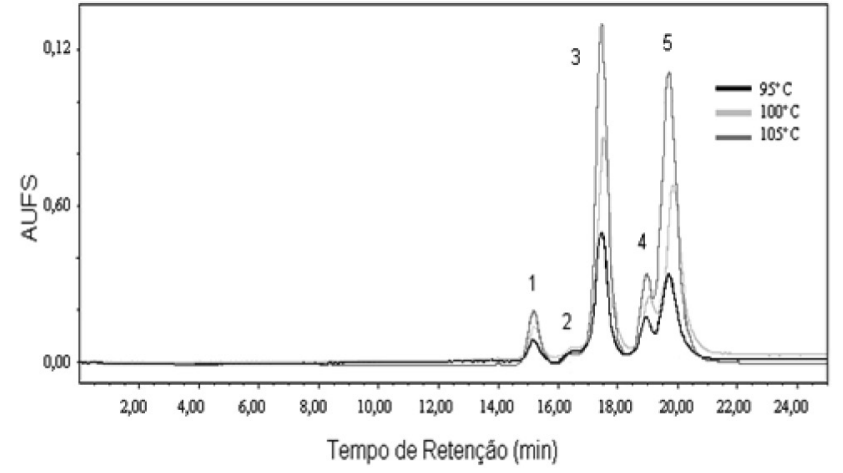

Figura 1. Sobreposição dos cromatogramas de uma amostra de café solúvel comercial $100 \%$ arábica conforme procedimento padrão de extração e análise para a temperatura do reator de 95; 100 e $105^{\circ} \mathrm{C}$. Pico: (1) glicose; (2) xilose; (3) galactose; (4) arabinose; (5) manose
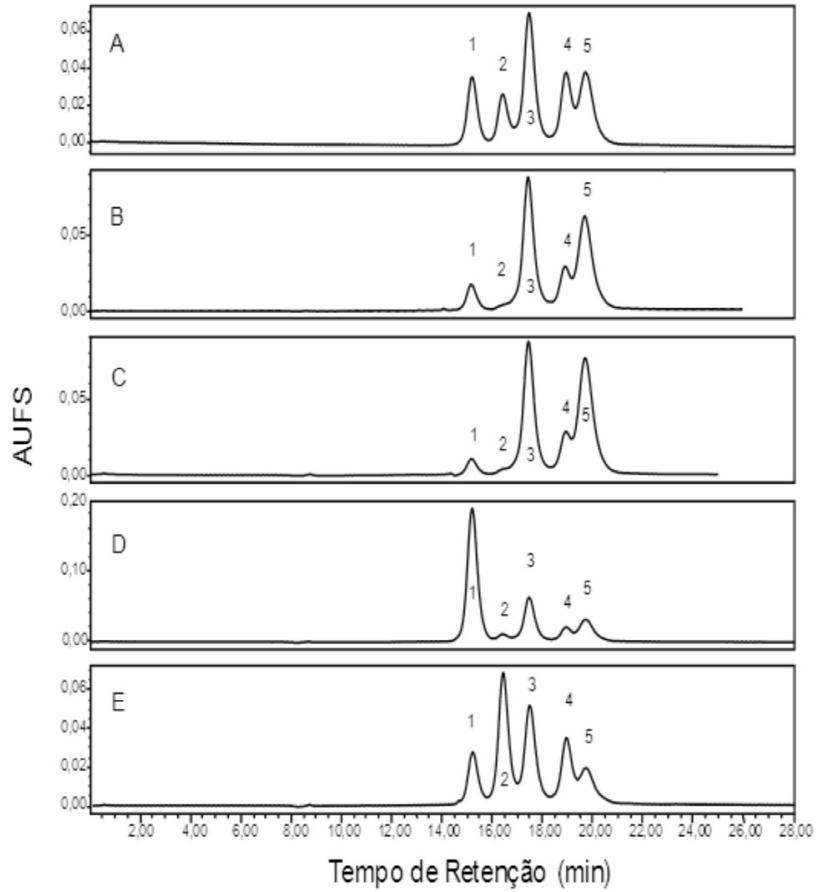

Figura 2. Cromatogramas com perfil de carboidratos para: (a) mistura de padrões a $25 \%(\mathrm{v} / \mathrm{v}),(\mathrm{b})$ café solúvel comercial $100 \%$ arábica, (c) café solúvel comercial $100 \%$ robusta, (d) café solúvel comercial adulterado com derivado de amido, (e) café solúvel comercial adulterado com casca de café

ainda notar a ocorrência dos elevados teores de galactose (pico 3) e manose (pico 5), monossacarídeos descritos como característicos para a matriz café. Já para os produtos adulterados, observa-se uma elevação da glicose (pico 1) quando adicionado derivado de amido, possivelmente milho ou maltodextrina (Figura 2d), ou ainda, adição de casca apresentado o aumento do teor de xilose (pico 2) na Figura $2 \mathrm{e}$.

Uma sobreposição dos cromatogramas de café arábica puro com os dois adulterados foi feita na Figura 3, para mostrar a diminuição no teor dos carboidratos galactose (pico 3) e manose (pico 5), na medida em que ocorre redução da proporção do café quando são misturadas outras matrizes, confirmando os dois grupos descritos por Ayra e Rao, ${ }^{10}$ que geram o aumento de glicose (pico 1) e xilose (pico 2) para casca e elevação de glicose (pico 1) para os amiláceos.

Embora utilizando técnica e metodologia distintas da literatura, e, portanto, de difícil comparação em termos quantitativos, é possível observar que nas amostras adulteradas os teores de xilose foram de

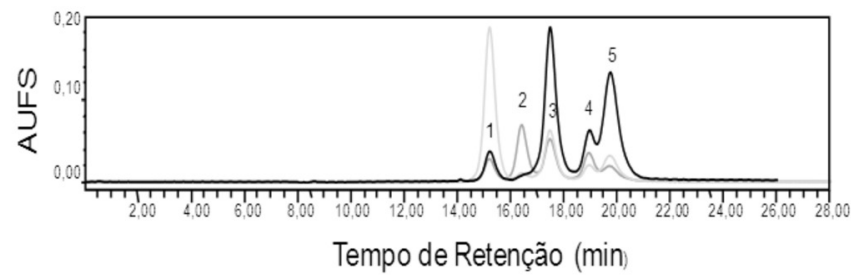

Figura 3. Sobreposição dos cromatogramas de amostras comerciais de café solúvel $100 \%$ arábica (linha preta mais intensa); café solúvel adulterado com derivado de amido (linha cinza claro) e café solúvel adulterado com casca de café (linha cinza escuro)

0,63 e $6,08 \%(\mathrm{~m} / \mathrm{m})$, maiores do que $0,40 \%$ descrito pela AFCASOLE, bem como os de glicose também se encontraram mais elevados com 18,90 e $2,82 \%$ em relação a $2,10 \%(\mathrm{~m} / \mathrm{m})$, comprovando a adulteração por produtos derivados de amido e casca, respectivamente. Assim, o uso desta metodologia se mostra uma alternativa viável para fins de triagem, uma vez que o detector UV-VIS é o mais comumente encontrado nos laboratórios e de operação mais simples, quando comparado ao eletroquímico (HPAE-PAD). Entretanto, para as amostras consideradas adulteradas recomenda-se submeter à metodologia oficialmente adotada internacionalmente normalizada pela ISO $11292,{ }^{13}$ para avaliação quantitativa.

\section{CONCLUSÃO}

A metodologia validada proposta para determinação de carboidratos totais em café solúvel empregando a HPLC-UV-VIS pós-coluna apresentou-se linear na faixa de concentração de trabalho, precisa, exata, específica e seletiva, o que garantiu resultados analíticos confiáveis que podem ser aplicados rotineiramente para efetuar triagem das amostras comerciais quanto à suspeita de adulteração, uma vez que se apresentaram compatíveis com a literatura, considerando os perfis e teores limites estabelecidos pela AFCASOLE.

\section{AGRADECIMENTOS}

À CAPES pelo suporte financeiro na forma de bolsa de estudos no Programa de Pós-Graduação em Química.

\section{REFERÊNCIAS}

1. Ferraz, M. B. M.; Farah, A.; Iamanaka, B. T.; Perrone, D.; Copetti, M. V.; Marques, V. X.; Vitali, A. A.; Taniwaki, M. H.; Food Control 2010, 21, 872 .

2. Farah, A. Em Functional and Speciality Beverage Technology; Paquin, P., ed.; Woodhead: New York, 2009, cap. 15.

3. http://www.ico.org/pt/coffee_storyp.asp, acessada em Abril 2010.

4. Nabais, J. V.; Carrott, P.; Carrott, M. M. L.; Luz, V.; Ortiz, A. L.; Bioresour. Technol. 2008, 99, 7224.

5. http://www.abic.com.br/scafe_historia.html, acessada em Abril 2010.

6. Assad, E. D.; Sano, E. E.; Cunha, S. A. R.; Correa, T. B. S.; Pesq. Agropec. Bras. 2002, 37, 211.

7. Santos, M. C. S.; Dissertação de Mestrado, Universidade Federal de Lavras, Brasil, 2005.

8. Bernal, J. L.; Del Alamo, M.; Del Nozal, M. J.; J. Agric. Food Chem. 1996, 44, 507.

9. Garcia, L. M. Z. ; Pauli, E. D.; Cristiano, V.; Camara, C. A. P.; Scarmínio, I. S.; Nixdorf, S. L.; J. Chromatogr. Sci. 2009, 47, 825.

10. Arya, M.; Rao, J. M.; CRC Crit. Rev. Food Sci. Nutr. 2007, 47, 51.

11. Femia, R. A.; Weinberger, R.; J. Chromatogr. 1987, 402, 127.

12. Vrátný, P.; Brinkman, U. A. T.; Frei, R. W.; Anal. Chem. 1985, 57, 224. 
13. International Organization For Standardization; ISO 11292. Instant coffee - Determination of free and total carbohydrate contents. Method using high performance anion-exchange chromatography, 1995.

14. http://www.dionex.com/en-us/webdocs/61831-Bro_Carbohydrates_ Food_Beverage_29Aug2007_LPN1971.pdf, acessada em Abril 2010.

15. Blanc, M. B.; Davis, G. E.; Parchet, J. M.; Viani, R.; J. Agric. Food Chem. 1989, 37, 926.

16. Redgwell, R. J.; Trovato, V.; Curti, D.; Fischer, M.; Carbohydr. Res. 2002, 337, 421.

17. Prodolliet, J.; Hischenhuber, C.; Z. Lebensm.-Unters. Forsch. A 1998, 207, 1.

18. Association des Fabricants de Café Soluble des Pays de la Communauté Européenne (AFCASOLE); Statement on Soluble Coffee Authenticity, $\mathrm{BD} / \mathrm{CPD} / 65 / 95,1995$.
19. Ribani, M.; Bottoli, C. B. G.; Collins, C. H.; Jardim, I. C. S. F.; Melo, L. F. C.; Quim. Nova 2004, 27, 771.

20. Lanças, F. M.; Validação de Métodos Cromatográficos de Análise, Rima: São Carlos, 2004.

21. Instituto Nacional de Metodologia, Normalização e Qualidade Industrial (INMETRO); Orientações sobre Validação de Métodos de Ensaios Químicos, Documento Orientativo: DOQ-CGCRE-008, 2007.

22. Zenebon, O.; Pascuet, N. S.; Tiglea, P.; Método Físico-Químicos para Análise de Alimentos, $4^{\mathrm{a}}$ ed., Instituto Adolpho Lutz: São Paulo, 2005, cap. 4.

23. Lever, M.; Anal. Biochem. 1972, 47, 273.

24. Honda, S.; J. Chromatogr., A 1996, 720, 183.

25. Brasil, Agência Nacional de Vigilância Sanitária (ANVISA); Resolução $R E n^{o} 899$, de 29/05/2003. 